$39^{\text {th }}$ AIAA /ASME/SAE/ASEE

Joint Propulsion Conference and Exhibit

Huntsville, AL

$20-23$ July 2003

\title{
EXPERIMENTAL PERFORMANCE EVALUATION OF A SUPERSONIC TURBINE FOR ROCKET ENGINE APPLICATIONS
}

\author{
Lauren M. Snellgrove, Lisa W. Griffin, James P. Sieja \\ Space Transportation Directorate \\ National Aeronautics and Space Administration \\ George C. Marshall Space Flight Center \\ Marshall Space Flight Center, AL \\ Frank W. Huber \\ Riverbend Design Services \\ Palm Beach Gardens, FL
}

\begin{abstract}
In order to mitigate the risk of rocket propulsion development, efficient, accurate, detailed fluid dynamics analysis and testing of the turbomachinery is necessary. To support this requirement, a task was developed at NASA/Marshall Space Flight Center (MSFC) to improve turbine aerodynamic performance through the application of advanced design and analysis tools. These tools were applied to optimize a supersonic turbine design suitable for a reusable launch vehicle (RLV). The hot gas path and blading were redesigned to obtain an increased efficiency. The goal of the demonstration was to increase the total-tostatic efficiency, $\eta_{t-s}$, of the turbine by eight points over the baseline design. A sub-scale, cold flow test article modeling the final optimized turbine was designed, manufactured, and tested in air at MSFC's Turbine Airflow Facility. Extensive on- and offdesign point performance data, steady-state data, and unsteady blade loading data were collected during testing. The predicted $\eta_{t-s}$ of the optimized design was 10.5 points higher than the baseline. Experimental results show that the goals of the TPO program have been met, by providing a detailed supersonic turbine dataset suitable for analytical code validation and showing a measured $\eta_{\mathrm{t}-\mathrm{s}}$ increase of 9 points over the baseline efficiency at design conditions.
\end{abstract}

Copyright 2003 by the American Institute of Aeronautics and Astronautics, Inc. No copyright is asserted in the United States under Title 17, U.S. Code. The U.S. Government has a royalty-free license to exercise all rights under the copyright claimed herein for Governmental Purposes. All other rights are reserved by the copyright owner

\section{NOMENCLATURE}

$\mathrm{bx}$
Isp
$\dot{m}$
$\mathrm{~N}$
$\mathrm{P}_{0}$
$\mathrm{P}_{\mathrm{r}}$
$\mathrm{P}_{\mathrm{s}}$
$\mathrm{R}$
$\mathrm{T}_{0}$
$\mathrm{~T}: \mathrm{W}$
$\mathrm{U} / \mathrm{C}$
$\mathrm{x}, \mathrm{y}, \mathrm{z}$
$\gamma$
$\eta_{\mathrm{t}-\mathrm{s}}$
$\eta_{\mathrm{t}-\mathrm{t}}$
$\theta$

\author{
Airfoil axial chord \\ Engine specific impulse \\ Mass flow rate \\ shaft rotational speed \\ inlet pressure \\ total-to-static pressure ratio \\ Static pressure \\ Radius, cylindrical coordinate \\ inlet temperature \\ Thrust to weight ratio \\ Velocity ratio \\ Cartesian coordinates \\ Ratio of specific heats \\ Total-to-static efficiency \\ Total-to-total efficiency \\ Tangential direction, cylindrical \\ coordinate
}

\section{INTRODUCTION}

NASA has implemented the Next Generation Launch Technologies (NGLT) program for the purpose of reducing the cost of access to space and to re-establish U.S. industry leadership among launch providers by addressing the required technology shortfalls. To aid in the development and to mitigate the risk of the propulsion system components, detailed fluid dynamics analysis and testing is needed. The analyses will be used to define the flowpath, investigate alternate design concepts, predict the performance, and characterize the fluid environment. An important area of analysis will be the turbomachinery, where fluid dynamics sets the shape of the blading and flowpath, and contributes greatly to the overall engine performance and durability. Turbine performance impacts rocket engine specific impulse (Isp), thrust-to-weight ratio 
(T:W), and reliability. This is true regardless of the engine cycle (although the degree of impact does depend upon the engine cycle). The capability to optimize turbine designs for performance and robustness leads to increased engine performance and reliability thereby reducing program cost and risk.

MSFC developed a task with the overall objective of developing and demonstrating advanced design and analysis tools to be used in the optimization of turbine performance. The design and analysis procedures that were developed for use on the Turbine Performance Optimization (TPO) project included one-dimensional (1D) tools, detailed two- and threedimensional (2D/3D) computational fluid dynamics (CFD) tools, and optimization techniques. The design and analysis tool development is documented in Huber', Dorney ${ }^{2}$, Griffin and Dorney ${ }^{3}$, Papila $^{4}$, et $a l$, and Vaidyanathan ${ }^{5}$, et al. These tools were applied to a supersonic turbine design suitable for an RLV. The goal of the application was to improve turbine efficiency by at least eight points over the baseline design. The application of these techniques in the TPO project is discussed in Griffin ${ }^{6}$, et al. A cold flow test article modeling the final optimized turbine was tested in air at the MSFC Turbine Airflow Facility from February 11, 2003 to March 5, 2003. This paper addresses the test series.

A sub-scale model of the TPO turbine was designed, manufactured, and tested in air. The test article was highly intstrumented with approximately 300 steady-state pressures and 80 steady-state temperatures along the walls of the flow path, on the surfaces of the vane, and on rakes at the exit of the turbine. Flow angles were also measured at the exit of the turbine. In addition, the first-stage blades were instrumented with high-frequency pressure transducers to measure the fluctuating pressures on the surface of the blades. Details of the unsteady data are given in Zoladz', et al.

The main purpose of the turbine performance optimization (TPO) turbine test was to verify the optimized turbine design and provide a detailed dataset suitable for validation of design and analysis tools. The resulting dataset is a unique, detailed dataset for a supersonic turbine with an unsteady dataset.

The specific test objectives were to: 1) measure and document turbine performance at design point; 2) measure and document aerodynamic loads at design point; 3) measure and document off-design turbine performance; 4) measure and document aerodynamic loads for off-design conditions; and 5) measure and document off-midspan aerodynamic loads. All test objectives were met, although schedule constraints limited the amount of off-design data collected. Analysis of the test data shows that the TPO task succeeded in the goal of improving turbine efficiency by at least eight points over the baseline design.

\section{FACILITY DESCRIPTION}

The test was conducted in the MSFC air flow Turbine Test Equipment (TTE). The TTE is a blowdown facility, which operates by expanding high pressure air from a 6000 cubic feet air tank at 420 psig to atmospheric or sub-atmospheric conditions. Air flows from the storage tanks through a regenerative thermal matrix heater section, quiet trim control valve, calibrated subsonic mass flow venturi, and into a plenum section. The air then passes through the test model and an exit pressure control valve before being exhausted to atmosphere. Subatmospheric exit conditions may be generated through the operation of an air ejector, fed by eight 1800 psig tanks, in the exhaust piping. In emergency situations, a quick acting valve opens for pressure equalization between the model inlet and the model exit.

This equipment can deliver 220 psia air for run times from 30 seconds to over 5 minutes. The heater allows a controlled temperature between $530^{\circ} \mathrm{R}$ and $830^{\circ} \mathrm{R}$. The TTE has manual set point closed-loop control of the model inlet total pressure, inlet total temperature, shaft rotational speed, and pressure ratio. In addition to these control parameters, the facility can accurately measure mass flow, torque, and horsepower. It is also capable of measuring 400 pressures, 120 temperatures, and various model health monitoring variables.

For this test series, core flow was heated to 300 ${ }^{\circ} \mathrm{F}$. The flow was exhausted to atmosphere for low pressure ratio runs and to sub-atmospheric pressure for higher pressure ratios. The drive train consisted of a dynamometer, a gearbox set at a 1:2 (dyno:model) ratio, and a torquemeter incorporating a $500 \mathrm{ft}-\mathrm{lbf}$ shaft. Before each run, a model preheat system was used to heat the model to near operating temperature in order to reduce the amount of time required to reach thermal stability.

\section{MODEL DESCRIPTION}

The test article was a sub scale $(70 \%)$ geometric replica of the full scale, supersonic, 2-stage, fulladmission TPO flow path. A cross section of the TPO test article is shown in Figure 1.

The model inlet flow was axially fed into the turbine with zero swirl. The first stage consisted of twelve airfoil-type vanes and thirty unshrouded impulse blades. The second stage consisted of seventy-three vanes and fifty-six unshrouded blades. The flow exhausted past exit guide vanes into an axial annulus, which lead to a collector. The collector directed the flow radially downward and diffused the flow to minimize the circumferential pressure 
gradient at the test article exit. Disk coolant flows and blade platform seal leakages were not simulated.

\section{INSTRUMENTATION}

The TPO model was instrumented for three purposes: (1) steady-state aerodynamic measurements to calculate loads and turbine performance; (2) fluctuating pressure measurements to calculate first stage blade loading and acoustic environment; and (3) model health monitoring measurements to ensure the safe operation of the model.

The turbine inlet plane had instrumentation placed on four stationary struts to measure inlet flow temperature and pressure. The model included static pressure measurements throughout the turbine rows. At five different axial locations, eight circumferentially spaced static pressure taps were located on the annulus outer and inner diameters. Instrumentation on the first vane included measurements at $50 \%$ span on both the pressure and suction vane surfaces, as well as measurements on the passage inner and outer walls. Second vane measurements were similar to the first vane measurements, with the addition of measurements at $10 \%$ and $90 \%$ span on the vane surfaces.

The turbine exit plane conditions were measured using an instrumented ring which could rotate $90^{\circ}$ about the model centerline. Rotation of the ring was controlled automatically from the control room. The ring contained four total pressure and four total temperature rakes positioned $90^{\circ}$ apart. Each rake had five radial measurement Kiel head probes. The exit rakes could be manually adjusted for swirl. Two auto-nulling Cobra probes were also mounted on the ring. These probes were positioned $180^{\circ}$ apart and were mounted on radial traverse actuators. These actuated probes allowed radial and circumferential surveys to be made of the flow angle in the yaw direction.

Fluctuating pressure measurements were installed on the outer flow path in the first vane passage, over the first rotor, in the second vane passage, and over the second rotor. Thirty Kulite miniature fluctuating pressure transducers were flush mounted and epoxies into pockets on the $1^{\text {st }}$ blade surfaces. The fluctuating pressure transducers were distributed over six blades, with locations on both suction and pressure surfaces. Most of the transducers were concentrated at midspan with 8 transducers total at $10 \%$ and $90 \%$ span. Software temperature compensation was used to improve the accuracy of the on-rotor pressure measurements.

The health monitoring and special purpose instrumentation included inlet rake and blade strain gauges, bearing outer race metal temperatures, speed pickups, accelerometers, and casing metal temperatures.

\section{DATA ACQUISITION EQUIPMENT}

The steady state pressures throughout the model and facility were measured using a Pressure Systems, Inc. (PSI) system. The individual pressure taps were connected to the PSI system via approximately 30 feet of 0.0625 inch nylon tubing. The type $E$ or $K$ thermocouple signals were measured using a HewlettPackard (HP) data acquisition unit. The HP unit was located next to the model and connected to the model with Type $E$ or $K$ wire via a patch panel. Once converted to a digital signal, the temperature measurements were sent to the control room.

The steady-state data acquisition process was driven by a 300 series HP computer. This unit served to coordinate communications between data acquisition equipment, allow user interfacing, and print out hard copies of the data.

Fluctuating pressure data was recorded using a system capable of digitally recording 32 channels of time-dependant data.

\section{TEST MATRIX}

Test article performance was evaluated at the design point and over a wide range of off-design conditions. The test set points were selected based on pressure ratio and isentropic velocity ratio $\left(\mathrm{U} / \mathrm{C}_{0}\right)$. The facility controls were inlet pressure, inlet temperature, pressure ratio, and speed. Table 1 overviews the test program parts.

\begin{tabular}{|l|l|l|}
\hline $\begin{array}{l}\text { Test } \\
\text { Part }\end{array}$ & Objective & Set Point Conditions \\
\hline A1 & $\begin{array}{l}\text { Check calibration } \\
\text { on on-rotor } \\
\text { transducers }\end{array}$ & $\begin{array}{l}\mathrm{T}_{0}=85,180,275^{\circ} \mathrm{F} \\
\mathrm{P}_{0}=15,47,65 \mathrm{psia} \\
\mathrm{P}_{\mathrm{r}}, \mathrm{N}=0\end{array}$ \\
\hline $\mathrm{A} 2$ & $\begin{array}{l}\text { Assess baseline } \\
\text { vibration }\end{array}$ & $\begin{array}{l}\mathrm{T}_{0}, \mathrm{P}_{0}, \mathrm{P}_{\mathrm{r}}=\text { no flow } \\
\mathrm{N}=4950 \text { to } 12500 \\
\mathrm{rpm}\end{array}$ \\
\hline $\mathrm{B}$ & $\begin{array}{l}\text { Record on-rotor } \\
\text { unsteady pressures }\end{array}$ & $\begin{array}{l}\mathrm{T}_{0}=300^{\circ} \mathrm{F} \\
\mathrm{P}_{0}=70 \mathrm{psia}\end{array}$ \\
& & $\begin{array}{l}\mathrm{P}_{\mathrm{r}}=4,8.71,12 \\
\mathrm{~N}=4950 \text { to } 12500 \\
\mathrm{rpm}\end{array}$ \\
\hline $\mathrm{C} 1$ & $\begin{array}{l}\text { Assess operational } \\
\text { thermal stability }\end{array}$ & $\begin{array}{l}\mathrm{T}_{0}=300^{\circ} \mathrm{F} \\
\mathrm{P}_{0}=70 \mathrm{psia}\end{array}$ \\
\hline $\mathrm{C} 2$ & $\begin{array}{l}\text { Map exit flow } \\
\text { angles }\end{array}$ & $\begin{array}{l}\mathrm{P}_{\mathrm{r}}=4,8.71,12 \\
\mathrm{~N}=4950 \text { to } 12500 \\
\mathrm{rpm}\end{array}$ \\
\hline $\mathrm{C} 3$ & Map performance & \\
\hline
\end{tabular}

Table 1. Test Series 
Series A included a series of set points to provide temperature vs. pressure calibration verification for the on-rotor instrumentation and to record a baseline vibration scan. Series B focused on collecting data to map the unsteady pressures on the blades of the first rotor.

Series $\mathrm{C}$ was divided into three parts and focused on steady-state performance data. Figure 2 shows the test envelope and test set points for series C. Series $\mathrm{Cl}$ assessed the thermal stability of the rig at various operating conditions. Series $\mathrm{C} 2$ focused on collecting exit flow angle data across the span of the flow path using two auto-nulling Cobra probes. The exit flow probes were used to measure the flow angles at five span-wise positions, corresponding to the rake measurement locations. For test series $\mathrm{C} 3$, the exit rakes were set to the mean measured flow angle. Data was collected from the rakes on the exit rotating ring with the ring at nineteen angular positions, in five degree increments, between zero and ninety degrees.

\section{DATA REDUCTION}

Data reduction consisted of two phases: (1) on-line calculations; and (2) off-line calculations plots and detailed analyses. On-line data calculations were performed immediately following the data acquisition process and were used to assess whether the run just completed was acceptable. On-line calculations were restricted to data from the current run. The calculations consisted of measurement averages and key overall performance parameters for each frame of data. Off-line calculations and plotting included:

(1) Plotting of raw data versus span, circumference, or axial location.

(2) Averaging of data and calculation of turbine performance parameters; plotting of average data and comparison of turbine performance to predictions.

(3) Analysis of run-to-run data and comparison to predictions; plotting of turbine performance curves.

\section{FLOWPATH ANALYSIS}

Meanline analyses were run for the test geometry with as-built areas and clearances for all test set points. The meanline design code (MLFPgen) developed for this study employs basic 1D turbine design equations coupled with loss correlations gleaned from experimental databases. The loss correlations include profile losses, Reynolds number effects, trailing edge blockage, secondary end wall losses, trailing edge shock losses, leading edge shock losses, and blade tip leakage losses. In addition to predicting performance, calculating gas conditions and velocity triangles, and generating a flow path elevation, the meanline analysis provides an initial span wise distribution of row exit angle based on a free or controlled vortex assumption. The off-design meanline code (MLOD) developed for the TPO project predicts performance and calculates velocity triangles and gas conditions for a given, fixed geometry. The analysis code employs the same loss correlations as the design code, but adds a profile loss due to incidence angle and an incidence correction due to secondary flows.

CFD was run for five set points (design point and four off-design points) with as-built areas and clearances. The governing equations considered in this study are the time dependent, 3D Reynoldsaveraged Navier-Stokes equations. To extend the equations of motion to turbulent flows, an eddy viscosity formulation is used. The turbulent viscosity is calculated using the two-layer algebraic turbulence model. The numerical algorithm used in the computational procedures consists of a time marching, implicit, finite-difference scheme. The procedures are third-order spatially accurate and second-order temporally accurate. Further information on the numerical procedure can be found in Dorney ${ }^{2}$ and Griffin and Dorney ${ }^{3}$.

CFD post-processing is in progress, so comparisons between CFD and data will be shown here only at design point. Additional information on the TPO analysis can be found in Dorney ${ }^{8}$, et al.

\section{RESULTS AND DISCUSSION}

\section{Qverall Performance}

Turbine efficiency was calculated both from the inlet-to-exit temperature drop and from the facility measured mechanical torque. As shown in Figure 3, results from the two methods agreed very well, producing efficiencies within 2 points of each other. Figure 4 compares the thermally calculated efficiency test results with the meanline and CFD code predictions. At design pressure ratio, the meanline code consistently overpredicts the efficiency by approximately 5 percentage points over the range of U/C. Predictions at the lowest pressure ratio, 4, showed the largest discrepancy with the data. The data shows similar efficiency levels for pressure ratios of 8.7 and 12.0, which is not observed in the meanline prediction. This finding suggests that the second stage is underexpanded at the design pressure ratio. CFD predictions of efficiency compare well with the data.

\section{Static Pressures}

The static pressure data shown is for the turbine design point. Figure 5 compares the static pressure drops across the turbine rows at the root and tip of the flow path for the test data, meanline prediction, and CFD predictions. The data shows a higher 
expansion across the first stage vane than was predicted. This expansion is due to an increase in area downstream of the vane that was in the as-built test article, but was not intended, or modeled with CFD. The data and the CFD prediction shows diffusion across the first stage blade, which the meanline does not predict, indicating an inaccuracy in the meanline loss models in the supersonic row. Figure 6 and Figure 7 compare the measured pressure distribution across the suction and pressure sides of the first and second stage vanes to the CFD results. The agreement between prediction and experiment is, in general, very good for both the vanes. The flow accelerates rapidly along the suction side of the first stage vane passage, terminating in a shock near $75 \%$ of the axial chord. The CFD slightly underpredicts the peak Mach number, but the as-built geometry should have higher exit Mach numbers than the asmodeled geometry, as previously discussed. Both the data and the prediction closely capture the flow acceleration and diffusion characteristics. The second stage vane is lightly loaded and exhibits negative incidence. The negative incidence results from the reaction in the experiment and CFD prediction being smaller in the second stage than the design intent.

\section{Swirl Angle}

Meanline turbine exit flow angles are shown in Figure 8. Positive flow angles are defined as opposite the direction of rotation of the turbine. The measured angles indicate less swirl than predicted, which correlates well with the lower measured efficiencies. Results from the pressure ratio of 4 show especially lower swirl, with negative swirl for high velocity ratios. Figure 9 shows all of the exit flow angles measured at design point. Measuring the flow at the outer radial locations was difficult, as the autonulling probes often could not lock onto the end wall flow. The scatter in the data at the outer radius is probably due to interactions between the probe and endwall. Figure 10 shows the mean radial distribution of flow angles at the turbine exit for a pressure ratio of 8.7. An interesting phenomena to note is the swirl angles at $U / C$ of 0.228 and 0.25 . The angle levels are similar when the expected amount of swirl at $\mathrm{U} / \mathrm{C}=0.25$ would be lower. Further investigations of these results are warranted.

\section{CONCLUSIONS}

A project to improve turbine performance through the application of advanced design and analysis tools and techniques was developed. These tools and techniques were applied to the redesign of an RLV supersonic turbine with the goal of achieving an efficiency improvement of at least 8 points. A test article of the resulting designed, manufactured, and tested in air. The test article was highly instrumented to provide detailed measurements. Testing covered a very wide range of off-design conditions. The resulting dataset was unique in its detail for a supersonic turbine with unsteady pressures measured on the supersonic blade. The dataset is useful for design and analysis tool verification and to improve the understanding of the flow physics in a supersonic turbine.

The meanline predictions were qualitatively good, but quantitatively mediocre for all points, and especially at low pressure ratios. The data indicates that this less than expected performance of the meanline code is caused by poor loss predictions in the supersonic blade row. Improvements to the leading edge shock model and the incidence model are necessary. Comparisons of data with the limited CFD predictions that are currently available is very good. Post-processing of further CFD predictions is continuing. Second stage performance is not as high as the design intent. CFD and data verify this lower performance.

The test data verified an efficiency improvement of at least 8 points over original design, confirming the achievement of the overall TPO design goal.

Because of issues with the model slip ring, measurements of unsteady pressures on the blades did not occur for many off-design cases. The TPO turbine model is scheduled to return to testing later in 2003 with the main goal of acquiring cleaner, more reliable on-rotor measurements. Unexplained phenomena that was observed in the first phase of testing, like the exit flow angle levels at design pressure ratio, will be investigated.

\section{REFERENCES}

1. Huber, Frank, "Turbine Aerodynamic Design Tool Development", presented at the Space Transportation Fluids Workshop, Marshall Space Flight Center, AL, April 2001.

2. Dorney, D. J., "Rapid Prediction of Unsteady Three-Dimensional Viscous Flows in Turbopump Geometries," NASA H-28721D Final Report, March 21, 1998.

3. Griffin, Lisa, and Dorney, Daniel, "Simulations of Unsteady Flow Through the Fastrac Supersonic Turbine", ASME Journal of Turbomachinery, Vol. 122, No. 2, April 2000, pp. 225-233.

4. Papila, Nilay, Shyy, Wei, Griffin, Lisa W., Huber, Frank, and Tran, Ken, "Preliminary Design Optimization for a Supersonic Turbine for Rocket Propulsion", AIAA Paper 2000-3242. July 2000 .

5. Vaidyanathan, Rajkuma, Papila, Nilay, Shyy, Wei, Tucker, Kevin, Griffin, Lisa, Haftka, Raphael, and Fitz-Coy, Norman, "Neural Network and Response Surface Methodology for 
Rocket Engine Component Optimization", AIAA Paper 2000-4880, September 2000.

6. Griffin, Lisa W., Dorney, Daniel J., and Huber, Frank W., "Design and Analysis of Turbines for Space Applications," AIAA Paper 2003-3993, Orlando, FL, June 23 - 26, 2003.

7. Zoladz, Thomas F, Griffin, Lisa W., and Dorney, Daniel J., "Experimental Blade Surface Pressure Distributions of a Supersonic Turbine for Rocket Engine Applications," AIAA Paper 2003-4916, Huntsville, AL July 21-23, 2003.

8. Dorney, Daniel J., Griffin, Lisa. W., Huber, Frank W., and Sondak, Douglas L., "Pre- and Post-Test Predictions of the Flow in a MultiStage Supersonic Turbine," AIAA Paper 20035071, Huntsville, AL, July 21-23, 2003. 


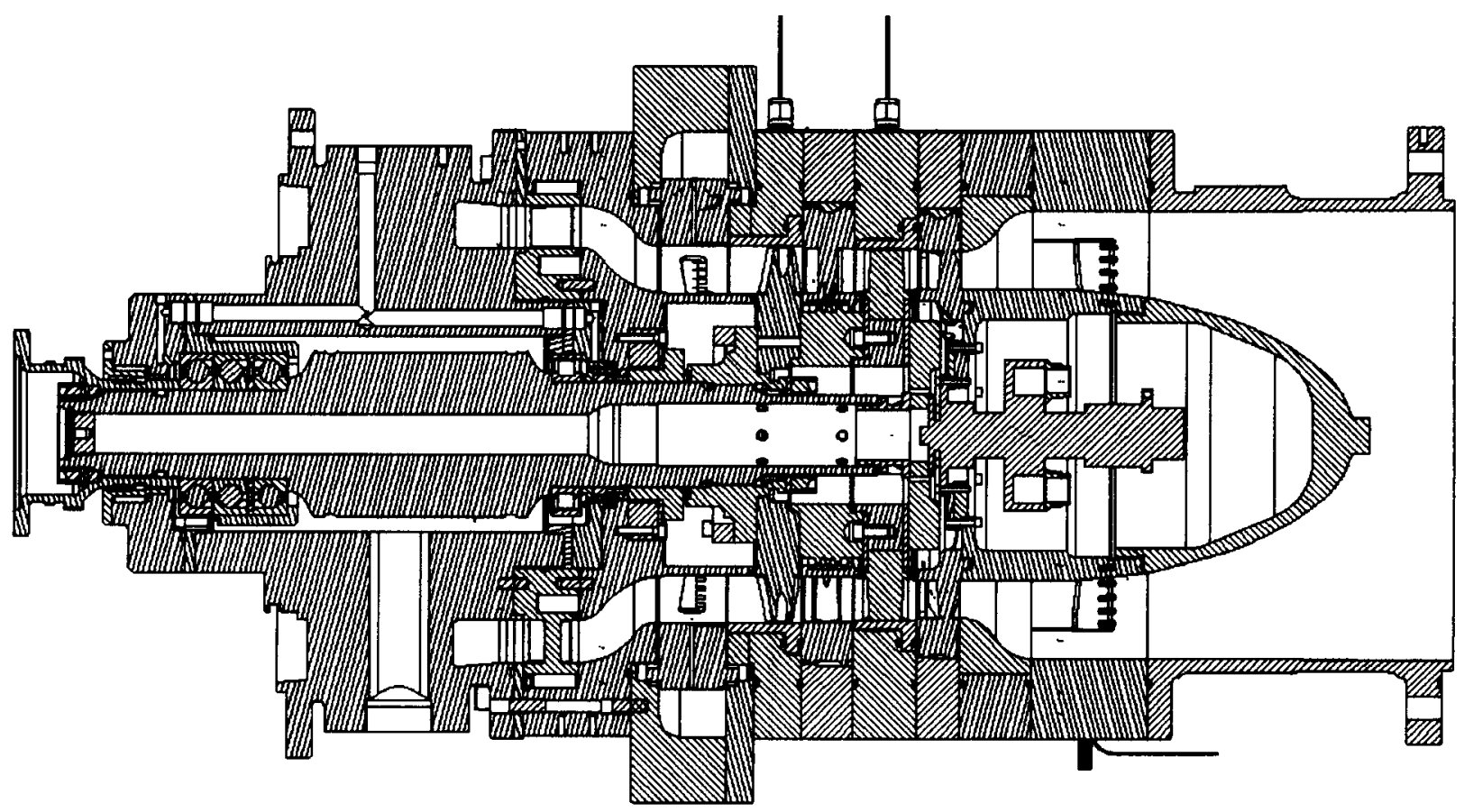

Figure 1. Cross Section of TPO Turbine

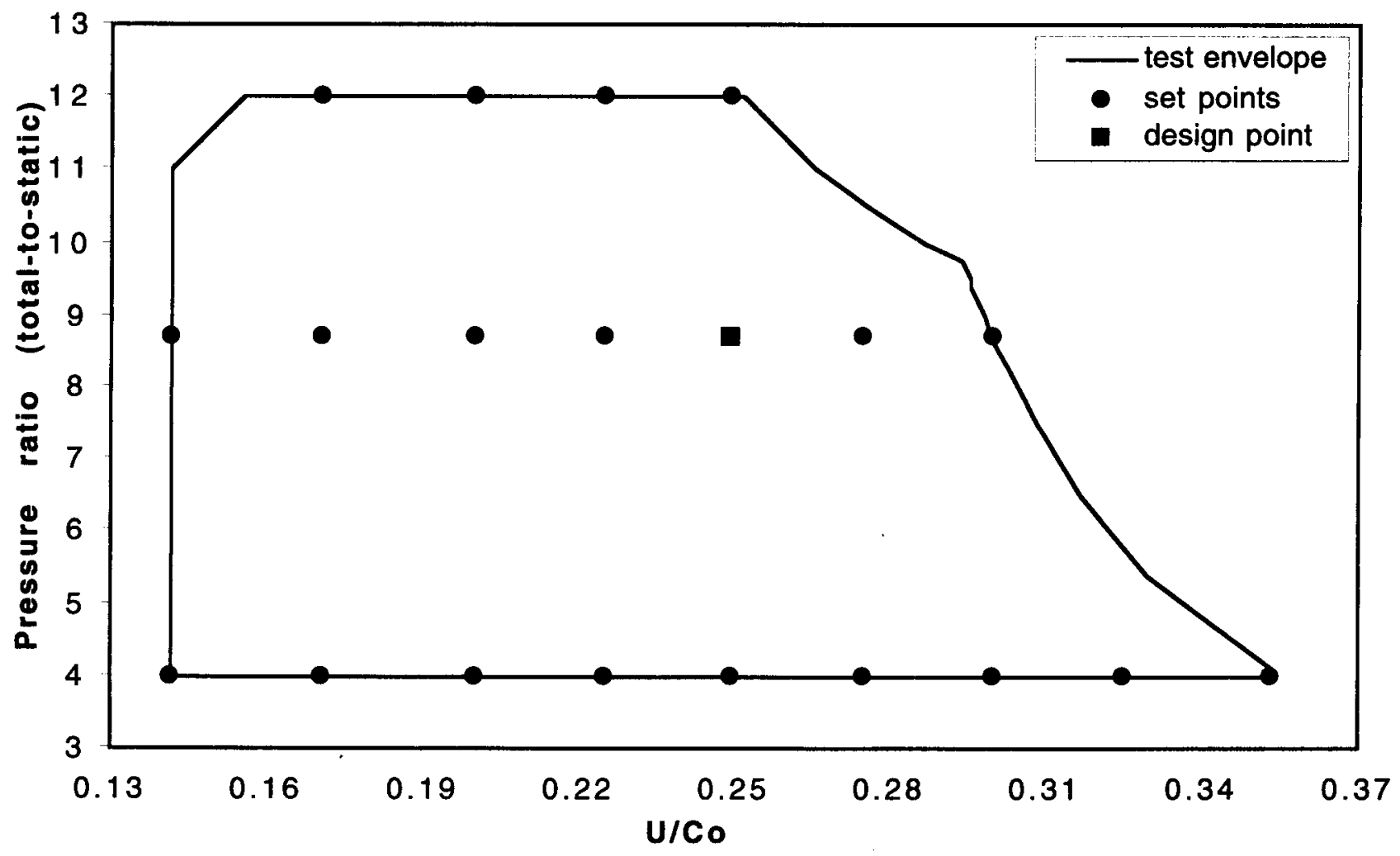

Figure 2. Non-Dimensional Operating Envelope 


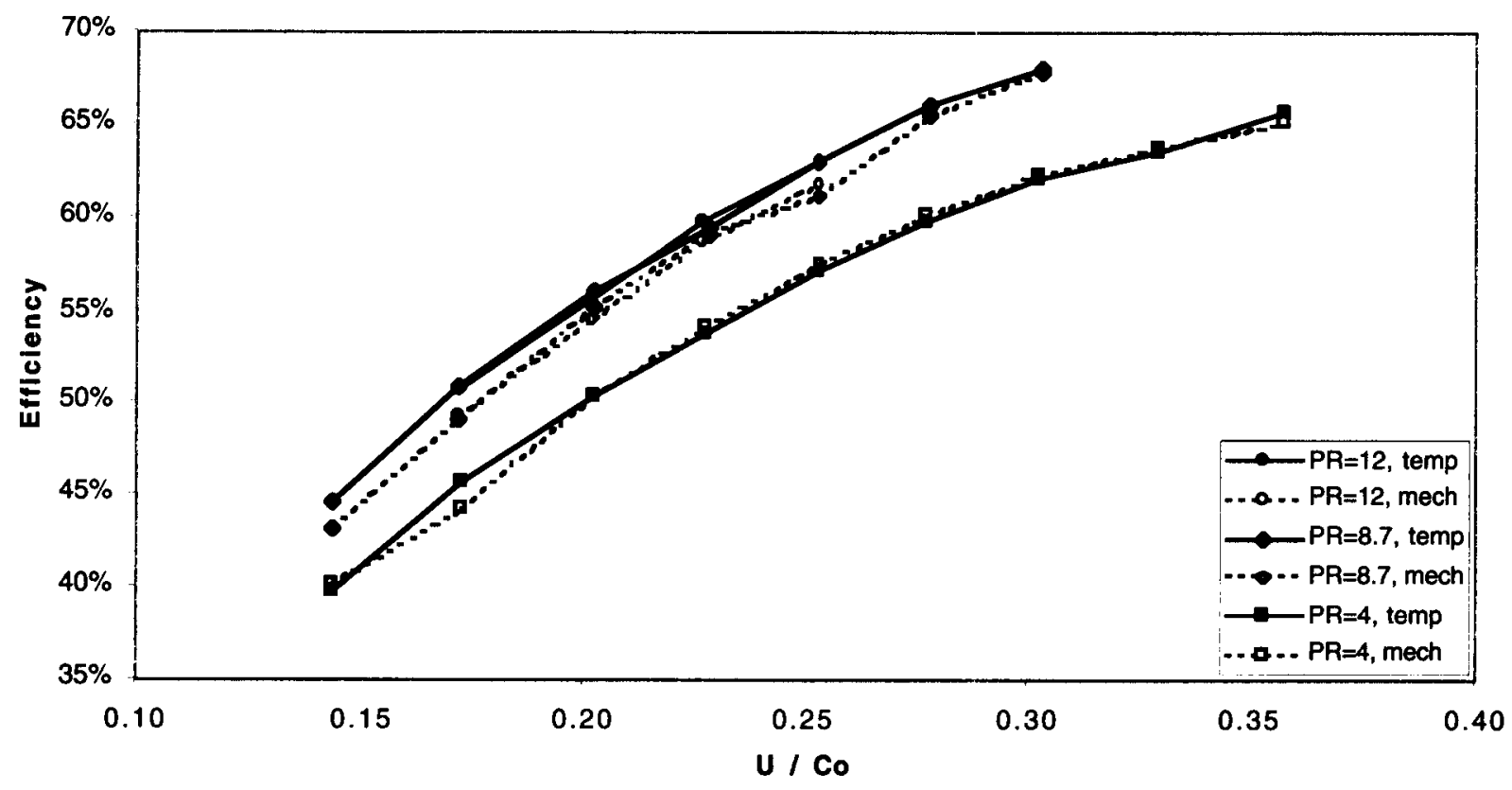

Figure 3. Thermal vs. Mechanical Turbine Efficiency

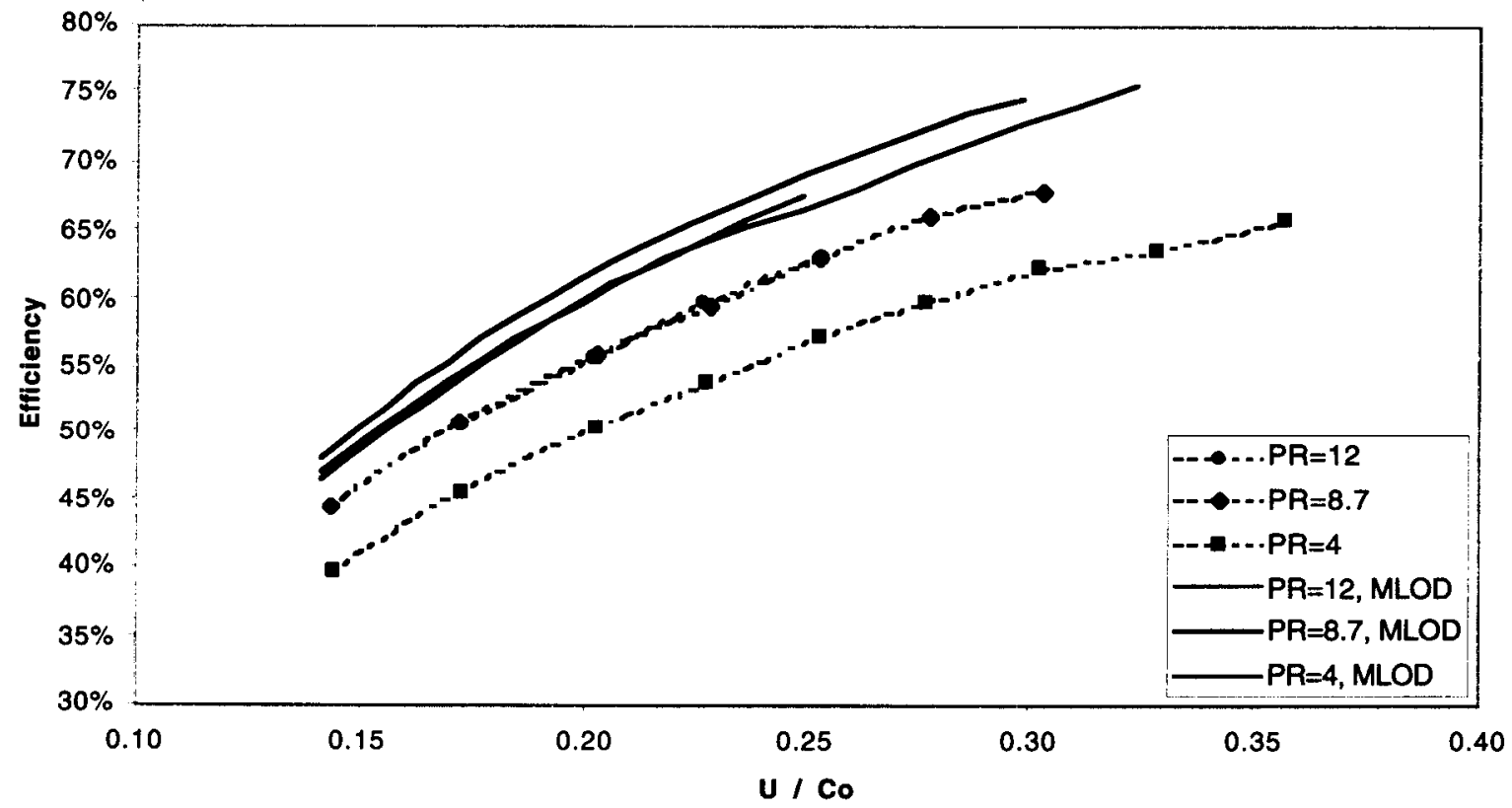

Figure 4. Test Data vs. Meanline Code Predictions of Turbine Efficiency 


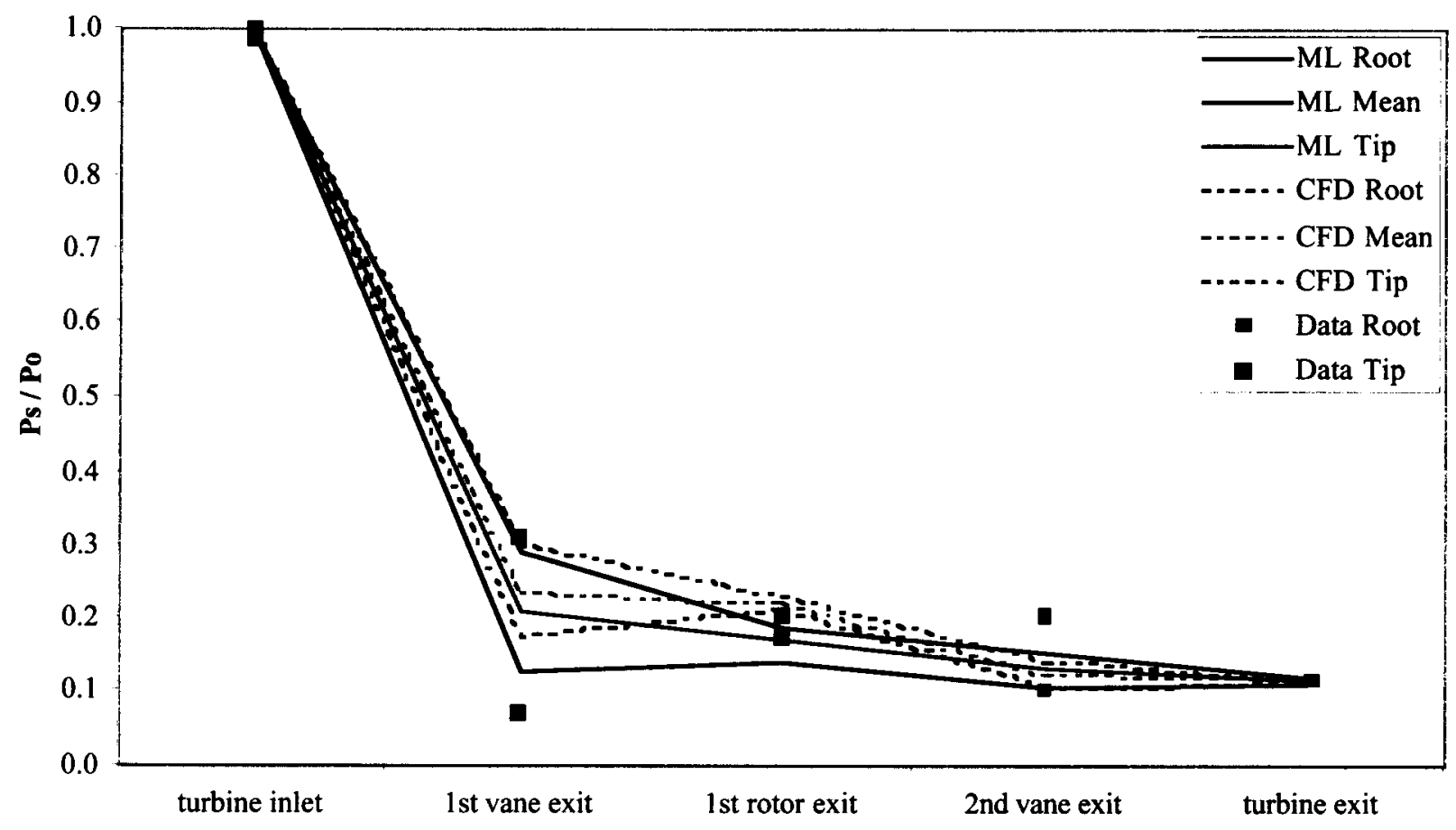

Figure 5. Row Static Pressure Drops at Design Point

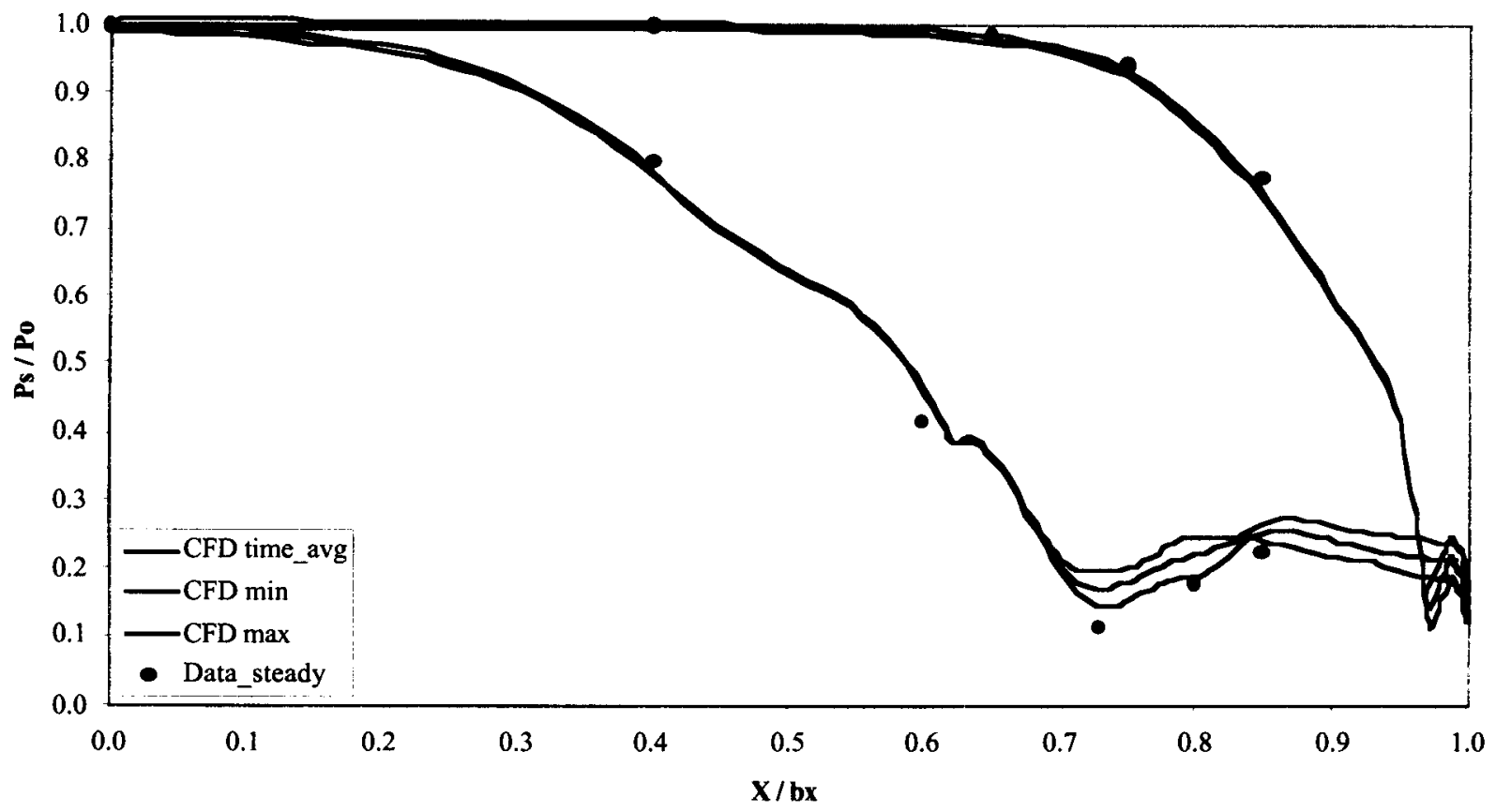

Figure 6. Pressure Distribution over $1^{\text {st }}$ Vane (50\% Span) at Design Point 


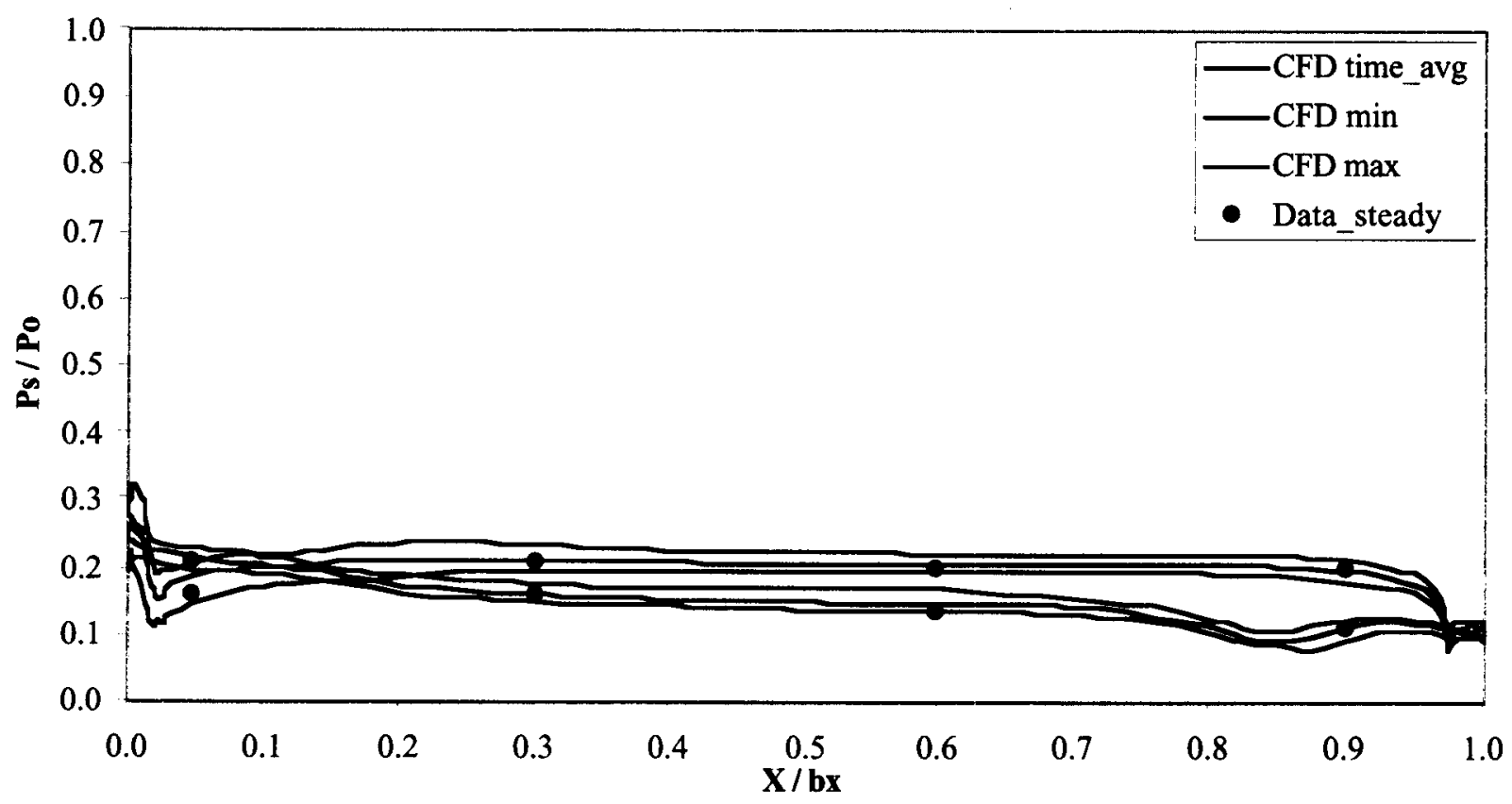

Figure 7. Pressure Distribution over 2ndVane (50\% Span) at Design Point

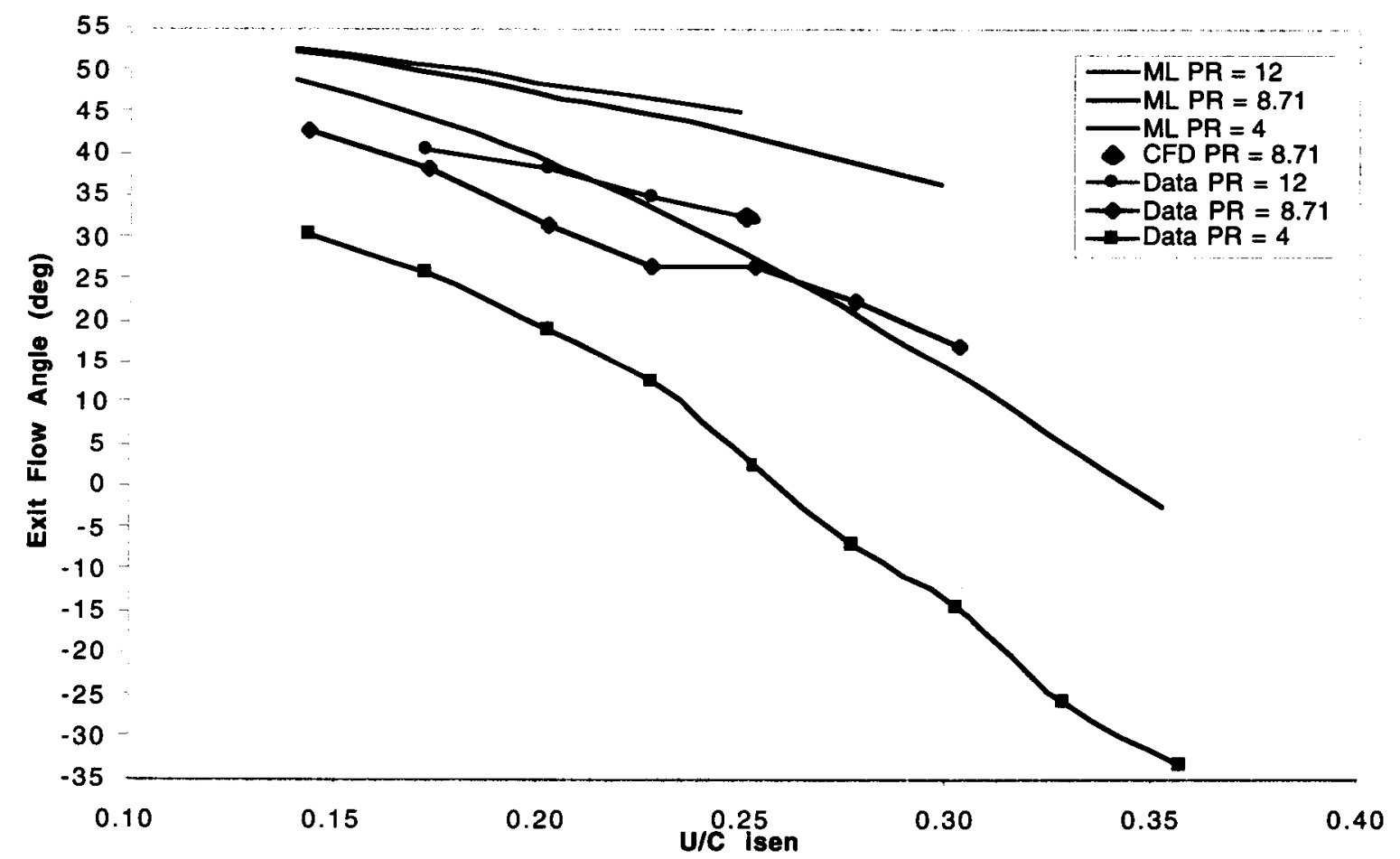

Figure 8. Meanline Exit Flow Angles 


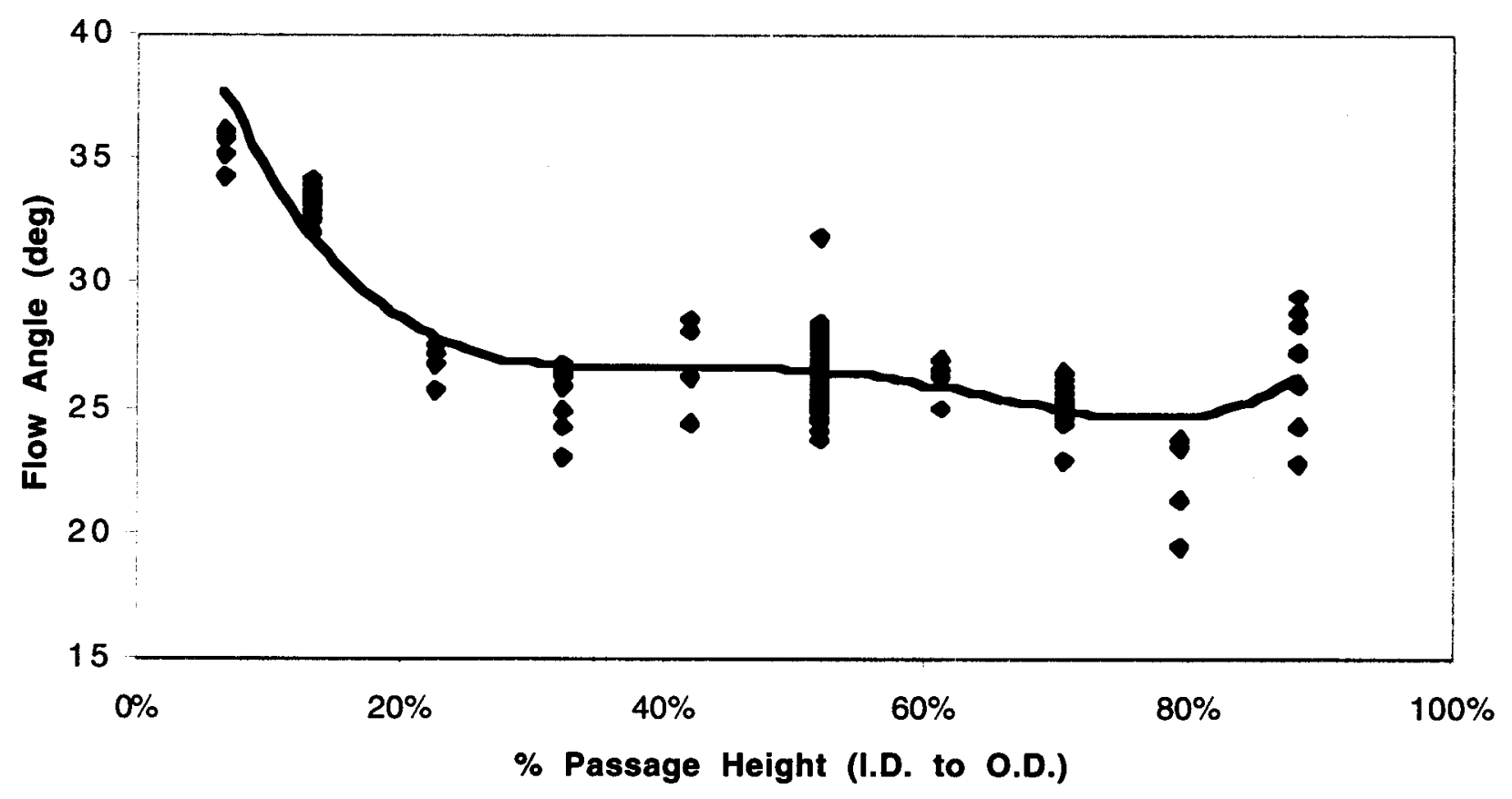

Figure 9. Exit Flow Angle Radial Distribution at Design Point

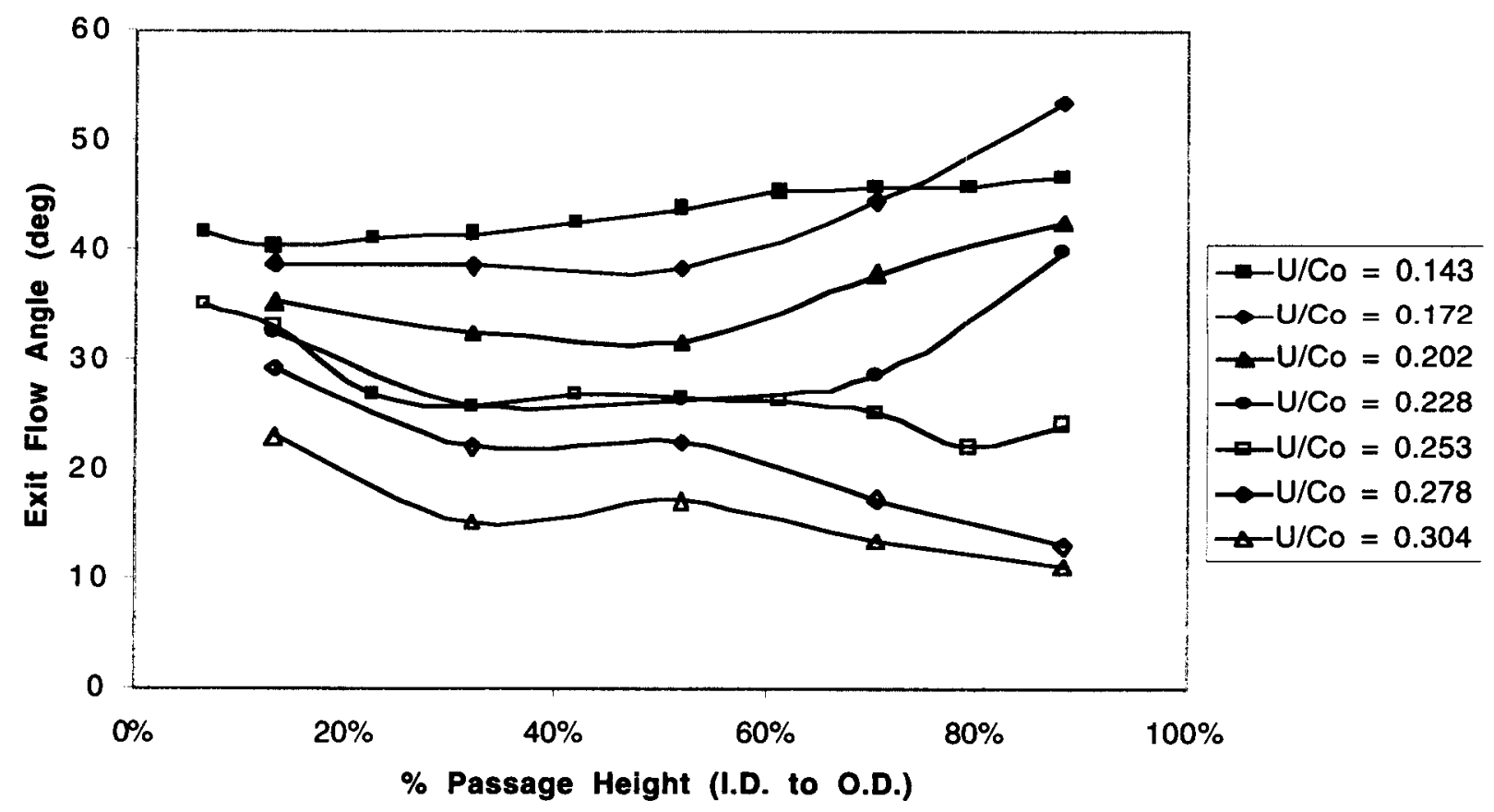

Figure 10. Radial Exit Flow Angles for Pressure Ratio $=8.7$ 